\title{
Potential adaptation strategies for climate change impact among flood-prone fish farmers in climate hotspot Uganda
}

\author{
Oyediran O. Oyebola ${ }^{1}$ D $\cdot$ Jackson Efitre ${ }^{2} \cdot$ Laban Musinguzi $^{3} \cdot$ Augustine E. Falaye $^{1}$
}

Received: 7 February 2019 / Accepted: 21 December 2020 / Published online: 9 February 2021

(c) The Author(s) 2021

\begin{abstract}
Climate-induced floods are increasing in Africa. The need to evolve framework for adaptation to climate change impact (CCI) among flood-prone fish farmers necessitated this study. Based on availability, 60 farming active flood-experienced fish farmers were purposively selected from flood-prone (Gulu and Kibuku) regions in climate hotspot Uganda. These were assessed for CCI adaptation tendencies in their socioeconomics and farming operation/techniques (FOI) indices, CCI awareness, CCI adaptation strategies, and perceived required interventions (RIs) using structured questionnaire. Data were analyzed through descriptive and multivariate regression tools. Respondents were mostly male, adults, educated, Christian, married, medium-sized family, social group members, 1-5 years' experience, medium-sized farms, and government trained. Income was 1.0-6.0 million Ugx/ year. In FOI, semi-intensive culture system, use of rainwater plus groundwater, small-sized $(<0.5 \mathrm{ha})$ ponds, ponds possession of inlets and outlets, seasonal farming and mixed culture/farming dominated. Most respondents were aware of CCI, while erratic rainfall with floods and prolonged drought mostly impacted farming. AS-Adaptation Strategy were changed stocking time and livelihood diversification. Communication technology and social group's membership enhanced adaptation, while inadequate awareness constrains adaptation. Respondents' RI(s) were tree planting, irrigation and pond perimeter trenching. Gender, government training, farm size, water sources and presence of inlet and outlets in ponds (FOI) predicted adaptation $\left(R=0.802, R^{2}=0.64, P<0.05\right)$. Some socioeconomic, technical and awareness indices could assist CCI flexibility. However, the statistically significant predictors of adaptation, identified adaptive strategies, constraints to adaptation and required interventions could be integrated into a framework for effective CCI adaptation for sustainable fish farming in flood-prone scenarios.
\end{abstract}

Keywords Fish farming $\cdot$ Climate risks $\cdot$ Flood-prone communities $\cdot$ Climate resilience

Oyediran O. Oyebola

olusegun.oyebola@yahoo.com

1 Department of Aquaculture and Fisheries Management, University of Ibadan, Ibadan, Nigeria

2 Department of Zoology, Entomology and Fisheries Sciences, Makerere University, Kampala, Uganda

3 National Fisheries Resources Research Institute (NaFIRRI), Jinja, Uganda 


\section{Introduction}

\subsection{Climate change and fish production sector}

Global warming is currently impacting rural communities. It has multi-sectoral dimensions, threatening social, political, and economic development of humans (Serdeczny et al. 2016). Africa is among the most vulnerable continents to climate change (New 2016), which takes multiple dimensions of disaster and food security (Freeman 2017; Ipinjolu et al. 2014; IPCC2012). Climate change impacts severely on natural systems, such as agriculture. This food production sector faces the daunting challenge of providing adequate food and other necessities to a growing world population. For now, the human population is projected to increase to nine billion by 2050 (Clements et al. 2011). Climate change contributes to poor and unpredictable yields, making farmers more vulnerable (UNFCCC 2007). Meanwhile, agriculture plays an essential role in many developing countries, which mostly run agro-based economies (World Bank 2008).

Fish production is an essential component of agriculture and global food security (Olaifa 2015). Billions of people around the world depend on fisheries and aquaculture for food, essential nutrients, and livelihoods (FAO 2016a). However, the global trend reflects that fish production from capture fisheries no longer meets demand (Gabriel et al. 2007). Fish stocks in African waters have been declining (Adebo and Ayelari 2011). The capture fishery subsector is being threatened by increasing climate change impact vulnerability (Boko et al. 2007; Allison et al. 2005). This climate scenario is expected to worsen in the future (Rhodes et al. 2014).

On the other hand, the aquaculture subsector of fish production continues to grow. Aquaculture is being noted as indispensable to meet the fish supply deficit, driving economic and social growth (FAO 2010). Aquaculture can serve as adaptation strategies to climate change impacts on fisheries (Coulibaly et al. 2007). It has great potential in ensuring food and nutrition security, especially in Africa (Olaifa 2015). Hence, it is gradually becoming the hope for fish production in the face of dwindling capture fisheries. Although many developing countries are increasingly adopting aquaculture in this regard, the subsector is also vulnerable to the impacts of climate change.

\subsection{Climate-induced flood in Africa: vulnerability of the fish farming subsector}

One of the main climate-induced threats to fish farming in Africa is flooding. There is increasing disasters of floods and drought in Africa (Gemeda and Sima 2015). Flooding is the most prevalent disaster in North Africa, the second most common in East, South, and Central Africa, and the third most common in West Africa (AWDR 2006). Floods generally impact livelihood across sectors but agriculture; especially, fish farming is being greatly impacted. Fish farming is likely to be more prone to flooding among agriculture subsectors. This is because flood-prone marshy/wastelands in agrarian communities are often converted to fish ponds. Meanwhile, the topography of marshy land is naturally vulnerable to flooding, with a probability of more flood intensity in the face of climate change influences. The impact could however vary based on nuances of the climate-induced floods, dimensions of topography, technical, and socioeconomic adaptive capabilities of fish farmers. 
Flood-prone communities would be more vulnerable to climate-induced flooding. The probability of vulnerability and impact would be relatively high among fish farmers. Meanwhile, challenges of this climate risk could inflict long-term negative influence on food security, human nutrition, livelihood, and economic condition, especially in the flood-prone agrarian communities. There is a need to plan for climate impact resilience among vulnerable groups such as the flood-prone fish farming communities in Africa.

\subsection{Sustainable fish farming in the face of climate-induced flood in Africa}

Sustainable fish farming requires both socioeconomic and technical capabilities, especially in the face of climate risks such as flooding. The socioeconomic status could facilitate response to climate risks because capital resources would be better channeled toward adaptation. Further to this, fish farming requires technical strength for sustainable success (Adelodun 2015; Nandi et al. 2014; Sarker et al. 2011). Technical skills support adaptation to climate risks in farming systems and can appreciably increase societal capacity to cope with floods, thereby decreasing overall impact (Alfieri et al. 2016; Adeleke and Omoboyeje 2016). Indigenous technological knowledge (ITK) is a key rescuer of people dwelling in flood-prone areas (Bordoloi and Muzaddadi 2014).

Socioeconomic and technical capabilities could be leveraged upon in climate impact resilience building for the fish production sector, particularly, for flood-prone fish farming communities. This would ensure sustainable fish farming despite flood risks. Some technical tools in this regard have been provided (Oyebola et al. 2018). These tools could be up taken for resilience. However, scientific knowledge on specific aspects of fish farming operations that determine the vulnerability of fish farming to climate change would be important to advocate for awareness creation and adoption of the techniques for improved resilience. It would be necessary to also highlight vulnerability indices among the socioeconomic profile of the fish farming communities to have holistic advocacy.

\subsection{Flood-prone zones and fish farming in climate hotspot Uganda}

Uganda is a climate hotspot country (Oratungye et al. 2016; Kahare 2014; Hepworth 2010). It ranks 15 th on vulnerability and 147 th on readiness for resilience to climate change and related events (Mer 2015). Ugandan economy and populations' wellbeing are tightly bound to climate (Hepworth and Goulden 2008). It has experienced the incidence of floods, desertification, distribution, and prevalence of pests and diseases (Environmental Alert 2010).

UNWFP/UNICEF/MOH (2007) reported that northern and eastern Uganda with high farmers' population is mostly affected by the flood, and there is the need for in-depth assessment of situations in the flood-prone areas. Muwaga et al. (2007) reported floods in the Teso region, eastern Uganda, while heavy rain and flooding occurs around the Gulu district in Northern Uganda (Davies 2017). These zones are among the base of agriculture in Uganda (Mwongera et al. 2014). Also, a majority of fish farmers in the country have not yet fully understood the fundamental principles of fish farming (Nelly et al. 2009). Hence, the technical capability of the fish farmers could be limited. Although awareness of fish farming is increasing in Uganda, the menace of climate change impact (CCI), especially climate-induced flooding, could frustrate the development of the fish farming subsector in Uganda. There is a need to build climate impact resilience, especially for fish farmers in the flood-prone zones of Uganda. This could be achieved through a boost in their adaptive 
capacity. However, such an effort requires knowledge of the potential adaptive capacity and the improvement needs for future survival.

The extent to which adjustments are possible in response to the actual or expected change in a system infers adaptability, and adaptive capacity plays a vital role in evaluating resilience. Appropriate climate impact adaptation strategies have been widely considered as a wealth of information that exists on climate change adaptation. However, much of such information is very broad and of limited use at the finer spatial scales, whereas adaptation strategies could vary by scales and sectors. The key considerations in adaptation could include issues on socioeconomic and environmental sectors; the main impacts of climate change in the future; climate-vulnerable regions; the array of adaptive options, key implications of climate change on related sectors and other environmental trends; the uncertainties and unknowns; policy and research implications (Parry 2000).

The impact of climate change would survive in future years and the actions toward adaptation would impair future impacts. The flood-experienced fish farmers in regions of climate hotspots such as Uganda are vulnerable and are facing uncertainties and unknowns. However, those who continued farming despite the hazard would have intrinsic adaptive options that have strengthened them to continue farming. A review of the way society has responded to climate change in the past suggests that society has tended to muddle through the challenges of its impact (Glantz 1988; Glantz and Kelman 2013). There is a possibility that vulnerable but surviving communities could have muddled through the climate and flooding threats. This could be based on their intrinsic socioeconomic and technical capacities, level of awareness, and adaptive innovations. However, improved future response to the hazard would require actions aimed at resolving the complications confronting the current adaptation strategies, and provision of assistance to cater for their observed mediation needs.

Therefore, the current study aims to investigate the adaptive tendencies of the socioeconomic and the technical profiles of the flood-prone fish farmers in the climate hotspot Uganda. It also examined their awareness of CCI manifestations; as well as adaptive strategies, constraints to adaptation, and required interventions. This was to evolve a framework for improved resilience for the fish farmers in similar scenarios. It is believed that such action would be beneficial to sustainable fish production in the face of climate change and climate-induced flooding, especially in Africa.

\section{Materials and methods}

\subsection{Study location}

Respondents for this study were obtained from the Kibuku and Gulu districts in the respective Teso and Acholi regions of the Eastern and Northern Uganda (Fig. 1). Teso region experienced heavy rainfall resulting in massive floods and destruction of homes and crops in 2006-07. Meanwhile, the frequency of climate change-induced floods is projected to increase on account of climate change, leading to considerable discomfort, loss of property, injury, and even loss of life in the northeastern parts of Uganda (The State of Uganda Population Report 2009). Teso region is one of the poorest in Uganda, suffering from cyclical floods, drought, famine, conflicts, and cattle raiding (Uganda humanitarian profile 2012). The unreliable weather, low agricultural productivity, and vulnerability to drought, floods, and waterlogging induced fragility on the food security situation of the 


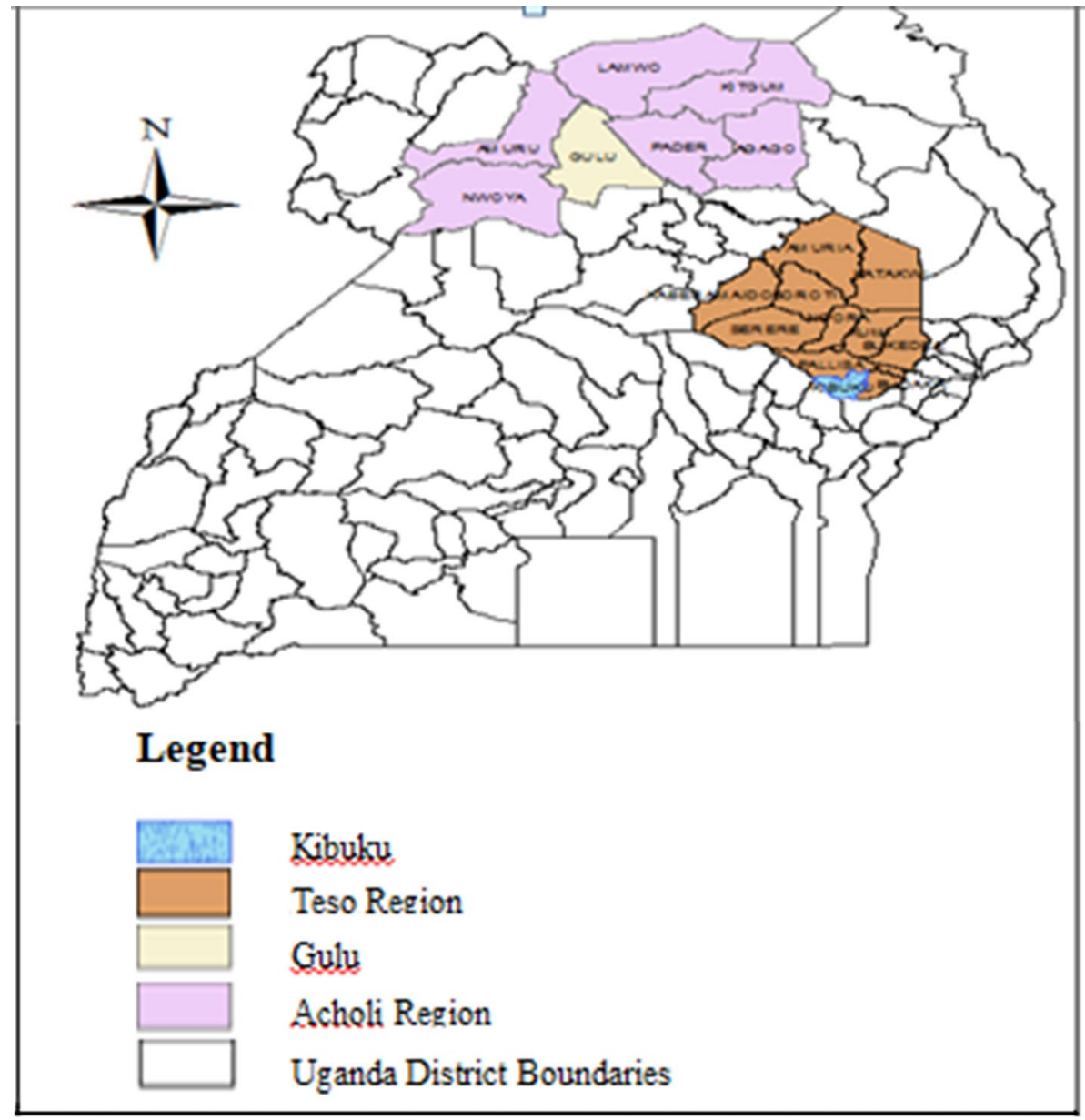

Fig. 1 Map of Uganda showing the studied locations

region. Kibuku is a district under the Teso subregion. It is located on latitude 1.016182 and longitude 33.86255 , at 12 meters above sea level. According to the Uganda Bureau of Statistics (2017), the district consists of Kibuku and Kabweri constituencies with a population of 202,033 people and 35,446 households. 93.7\% of households engaged in crop growing, $68.1 \%$ in livestock, and $95.2 \%$ combined crop and livestock farming. Other livelihood includes off-farm activities like "Bodoboda" cycling, blacksmiths, fishing, charcoal and local brewing "Ajono" trade, brick making, stone, and sand quarrying among others. Kibuku district is prone to climate-induced flooding (Flood map 2020). Heavy rains pounded some parts of the eastern region in mid-March 2017 washing away bridges on the Mbale-Tirinyi road at Sala in Kibuku District, Nasanga located between Budaka and Kibuku districts, and Nandusi in Budaka District cutting off the Mbale-Tirinyi road (Kolyangha 2017). The Acholi region has a generally flat topography, with predominantly sandy loam soils. The Uganda IPC (2017) reported that change in weather pattern/dry spell, late arrival, poorly distributed; inconsistent and insufficient rainfall negatively affects good crop production in Acholi. Gulu is among the eight districts in the Acholi region. It is on 
latitude 2.77165, longitude 32.29776, at 18 meters above sea level. Severe effects of floods have displaced up to 300,000 people in Uganda, while heavy rains are expected to continue in the Northern and Eastern parts of Uganda; including the districts of Mbale, Manafwa, Bukeda, Budadu, Kumi, Soroti, Katakwi, Amuria, Lira, Pader, Kitgum, Nebbi, Gulu and scattered areas of central Uganda (IFRC 2007). Gulu consists of the Gulu municipality and Aswa county constituencies with a total population of 275,613 and 55,441total households. $64.4 \%$ of households engaged in crop production, $54.0 \%$ livestock, and $72.0 \%$ combined livestock and crop (Uganda Bureau of Statistics 2017). There is no significant change in livelihoods except for the prolonged dry spell that affected the provision of agricultural casual labor (Uganda IPC 2017).

\subsubsection{Geography and climate of studied locations}

Uganda lies within a relatively humid equatorial climate zone. The topography, prevailing winds, lakes, and rivers cause large differences in rainfall patterns across the country. Changes in sea surface temperatures in the distant tropical Pacific, Indian, and, to a lesser extent, Atlantic Oceans strongly influence annual rainfall amounts and timing. Climate variation pattern over a 60-year historical record for Uganda indicates climate change (Uganda climate change vulnerability assessment report 2013).

A comprehensive report on the climate of Uganda was presented by Mer (2015). Temperature varies with altitude and changes little from season to season. There are two main seasons in southern and eastern Uganda (March to May and September to November), while April to October constitutes the main season in the north. According to weatherspark.com, in the Soroti axis including Teso, summers are short, hot, dry, and overcast. The hot season lasts for about three months, from mid-December to mid-March, while the cool season lasts from late April to early September.

Year to year variation in annual rainfall occurs. Generally, the onset of seasons can shift by 15-30 days. There is a modest decrease in annual rainfall in the northern region consisting of the Gulu-Acholi area, Kitgum, Kotido, and Kasese. The mean annual temperature of about $23{ }^{\circ} \mathrm{C}$ occurs in Gulu and $24.6{ }^{\circ} \mathrm{C}$ for Kitgum (Mwongera et al. 2014). Teso has savannah vegetation type and has suffered from various disaster-related challenges; floods becoming almost annual events during wet seasons (The Teso-Bukedea District Hazard, Risk and Vulnerability Profile 2014). It experiences a bimodal type of rainfall of about 1 000-1 $200 \mathrm{~mm}$ per annum with two cropping seasons. The first rainy season comes in late March to June, while the second rainy season is from late July to October. However, this pattern has been erratic with uneven distribution across the region in recent years (Uganda IPC 2017).

\subsection{Research design}

A purposive descriptive survey method was adopted for this study. Kibuku and Gulu districts were purposively surveyed which consist mainly of agrarian people whose flooding sources are more of nature than those of metropolitan in which high population density and industrial activities contribute to flooding in addition to climate-induced situation. Flood-experienced respondent fish farmers were purposively selected from the flood-prone Kibuku and Gulu areas in respective Teso and Acholi regions of Uganda for the study. 30 respondent fish farming households were selected across each of the Gulu and Kibuku areas based on availability to have a pool of 60 respondents. Interaction 
with stakeholders during the pre-survey period showed these sets of farmers were available at Gulu and Kibuku; hence, these locations were purposively surveyed for these sets of farmers. The pooled 60 respondents represent the study population who were the flood-prone, and flood-experienced but still farming despite flooding individuals. These were selected from the agrarian communities (Gulu and Kibuku) based on availability for questioning. The respondents were obtained through farmers associations, while fisheries extension officers were utilized as identifiers and enumerators. This survey method was adopted because the estimated population size of the fish farmers in the study area was not feasible, as fish farmers and livestock farmers were referred to as livestock farmers, no separation. Fish farmers' names were therefore identified from general farmers list based on the extension agent's ability to identify them as members of farmers association that were operating fish farm. The questionnaire was then administered to the identified farmers, based on his/her availability and accessibility to the extension agents for questioning. Responses were revalidated during farm visits to a subsample of the respondents at each of the selected flood-prone locations.

\subsection{Data Collection Framework}

Secondary data were obtained from the literature, while primary data were collected from the study survey. During the survey, information was extracted from respondent fish farmers on socioeconomics, farming operation, awareness on the manifestation of climate impact, and extreme climate events that mainly impacted fish farming, adaptation strategies, and constraints to adaptation, as included in the structured questionnaire.

The design and administration of the questionnaire followed Dubey et al. (2017). The questionnaire was designed with open- and close-ended questions. Attempts were made to make the language of the questionnaire unambiguous, brief, polite, and nontechnical. The questionnaire was prepared in English language and interpreted to local dialect wherever necessary, to facilitate enhanced understanding by respondents, and to increase the effectiveness of survey results.

The questionnaire was pretested with selected key informants including academics, farmers, and fisheries extension officers at the two flood-prone communities in two different meetings. This was carried out to identify ambiguous questions, upon which, adjustments were made. Enumerators were selected, trained on the details of the questionnaire, and engaged for the survey. The obtained data were analyzed and the results were utilized to suggest a framework for adapting to climate change among floodprone fish farmers for sustainable fish farming in the face of climate-induced flooding. The study survey and data collection were carried out following stringent ethical considerations.

\subsection{Statistical analysis}

Data on profiles of socioeconomics, fish farming operation, awareness on climate change indices, adaptive strategies, constraints to adaptation, and required interventions were presented using descriptive statistics. A significant predictor of adaptive capacity was extracted through multivariate regression of response on adaptation strategies with socioeconomic and farming operation indices on SPSS version 20.0. 


\section{Results}

\subsection{Socioeconomic and technical profiles of the fish farmers}

\subsubsection{Socioeconomics}

The socioeconomic indices (SEI) (Table 1) showed $83.3 \%$ male, $68.3 \%$ adult; $80.0 \%$ literate (primary to tertiary school), 91.3\% Christian (sum of Catholic, Anglican, and Born again sects); $91.7 \%$ married and $48.3 \%$ (majority) medium household sized (5-8 members, mean $=2.02 \pm 0.73$ ). Total annual income ranged from 1.0 to $>5.0$ million Ugx/ year; equivalent to 264.32 to $1321.62 \mathrm{USD}$, with mean at $1171.03 \pm 491.67 \mathrm{USD} /$ year. All respondents (100.0\%) engaged in other livelihood activities with a mean income of $3.70 \pm 1.03$ million Ugx/yr. Respondents also engaged in fishing (16.7\%), crop farming $(100.0 \%)$ animal husbandry (23.3\%), public service $(33.3 \%)$ and trading (21.7\%). Majority (60.0\%respondents) had medium-size farms (0.5-1.0 ha), with $100.0 \%$ having $1-5$ years' fish farming experience. Most respondents (65.0\%) were members of social groups $(63.3 \%$ belonging to fish farmers group), $81.7 \%$ had knowledge of fish farming through government training, while $98.3 \%$ utilized communication technologies, especially mobile phones (91.7\% respondents).

\subsubsection{Technical/farming operation}

As presented in Table 2, all (100.0\%) respondents utilized freshwater, $38.3 \%$ rainwater only, and $61.7 \%$ rainwater plus groundwater. About $16.7 \%$ operate the extensive farming system, while $83.3 \%$ operate semi-intensive systems. Total pond area ranged between $<0.5$ ha $(56.7 \%$ respondents) and $>0.5-1.0$ ha ( $43.3 \%$ respondents). $100.0 \%$ of ponds were seasonal, and $61.7 \%$ had inlet and outlet in all ponds. $58.3 \%$ of respondents practiced monoculture of African catfish (Clarias gariepinus), 3.3\% monoculture of Nile tilapia (Oreochromis niloticus), and $38.4 \%$ practiced polyculture of the African catfish and Nile tilapia, while $100 \%$ practiced mixed farming/integrated aquaculture. Most respondents (96.7\%) preferred African catfish culture, while $15.0 \%$ do fish smoking for value addition.

\subsection{Awareness on manifestations of climate change impacts}

Respective $83.3 \%$ and $100.0 \%$ of respondents were aware of changes in climatic conditions and the presence of dry and wet seasons in a year (Table 3). Most respondents $(80.0 \%)$ were aware of rises in temperature and hotter dry seasons. Meanwhile, $60.0 \%$ were aware of irregularities in seasons, shortening of the wet season, drought, decrease in river water volume concerning rain and $45.0 \%$ of respondents were aware of erratic rainfall patterns and flood. The majority were aware of low rainfall (83.3\%), late onset of rainfall $(80.0 \%)$, shortening of rainy seasons $(71.7 \%)$, and heavy land erosion $(71.7 \%)$; minority on heavy rainfall at the onset of the season $(18.3 \%)$, the late offset of the rainy season $(41.7 \%)$, early offset of the rainy season $(8.3 \%)$, increased frequency of violent storms (18.3\%) and increased frequency of heavy downpour of rain with storms (18.3\%). Meanwhile, the identified most important extreme climate manifestations that have negatively impacted on fish farming operations were prolonged drought $(83.3 \%)$ 
Table 1 Socioeconomic indices of respondents

\begin{tabular}{|c|c|c|c|}
\hline Socioeconomic characteristics & Category & Frequency & $\begin{array}{l}\text { Percent } \\
\text { respond- } \\
\text { ent }\end{array}$ \\
\hline \multirow[t]{2}{*}{ Gender } & Male & 50 & 83.3 \\
\hline & Female & 10 & 16.7 \\
\hline \multirow[t]{2}{*}{ Age } & Youth (<35 yrs) & 19 & 31.7 \\
\hline & Adult (>35 yrs) & 41 & 68.3 \\
\hline \multirow[t]{4}{*}{ Education } & None & 12 & 20.0 \\
\hline & Primary & 16 & 26.7 \\
\hline & Secondary & 17 & 28.3 \\
\hline & Tertiary & 15 & 25.0 \\
\hline \multirow[t]{4}{*}{ Religion } & Catholic & 19 & 31.7 \\
\hline & Anglican & 28 & 46.7 \\
\hline & Moslem & 5 & 8.3 \\
\hline & Born again & 8 & 13.3 \\
\hline \multirow[t]{2}{*}{ Marital status } & Not married & 5 & 8.3 \\
\hline & Married & 55 & 91.7 \\
\hline \multirow[t]{3}{*}{$\begin{array}{l}\text { Household size } \\
\text { Mean }=2.02 \pm 0.73\end{array}$} & $\begin{array}{l}<4 \text { members } \\
\text { (small) }\end{array}$ & 15 & 25.0 \\
\hline & $\begin{array}{l}5-8 \text { members } \\
\text { (medium) }\end{array}$ & 29 & 48.3 \\
\hline & $\begin{array}{l}>8 \text { members } \\
\text { (large) }\end{array}$ & 16 & 26.7 \\
\hline \multirow[t]{4}{*}{ Membership to social groups } & Yes & 39 & 65.0 \\
\hline & Fish farmers' groups & 38 & 63.3 \\
\hline & Religious & 1 & 1.7 \\
\hline & No membership & 21 & 35.0 \\
\hline \multirow[t]{4}{*}{ Use of communication technologies } & Yes & 59 & 98.3 \\
\hline & Mobile phone & 55 & 91.7 \\
\hline & Radio & 32 & 61.7 \\
\hline & Television & 1 & 1.7 \\
\hline \multirow{5}{*}{$\begin{array}{l}\text { Other livelihood activities } \\
\text { (Mean annual income }=3.70 \pm 1.03 \text { ) }\end{array}$} & Fishing & 10 & 16.7 \\
\hline & Crop farming & 60 & 100.0 \\
\hline & Animal husbandry & 14 & 23.3 \\
\hline & $\begin{array}{l}\text { Formal employment } \\
\text { (public service) }\end{array}$ & 20 & 33.3 \\
\hline & Trading & 13 & 21.7 \\
\hline \multirow[t]{3}{*}{ Farm size } & $\begin{array}{l}<0.5 \text { ha } \\
\text { (small) }\end{array}$ & 22 & 36.7 \\
\hline & $\begin{array}{l}0.5-1.0 \text { ha } \\
\text { (medium) }\end{array}$ & 36 & 60.0 \\
\hline & $\begin{array}{l}1.0-3.0 \text { ha } \\
\text { (large) }\end{array}$ & 2 & 3.3 \\
\hline Fish farming experience & $1-5 \mathrm{yr}$ & 60 & 100.0 \\
\hline \multirow[t]{3}{*}{ Knowledge sources } & Government training & 49 & 81.7 \\
\hline & NGO training & 47 & 78.3 \\
\hline & Other farmers & 21 & 35.0 \\
\hline
\end{tabular}


Table 1 (continued)

\begin{tabular}{|c|c|c|c|}
\hline Socioeconomic characteristics & Category & Frequency & $\begin{array}{l}\text { Percent } \\
\text { respond- } \\
\text { ent }\end{array}$ \\
\hline & Mass media & 0 & 0.0 \\
\hline \multirow{6}{*}{$\begin{array}{l}\text { Total average annual income (Ugx/yr.) } \\
(\text { Mean }=4.43 \pm 1.86)\end{array}$} & 1.0-2million (264.32-528.65USD) & 14 & 23.3 \\
\hline & >2-3millions (528.65-792.97USD) & 3 & 5.0 \\
\hline & $>3-4$ millions (792.97-1057.30USD) & 3 & 5.0 \\
\hline & $>4$-5millions (1057.30-1321.62USD & 2 & 3.3 \\
\hline & $>$ 5millions $(>1321.62$ USD $)$ & 21 & 35.0 \\
\hline & Invalid & 17 & 28.4 \\
\hline
\end{tabular}

Table 2 Technical/operational fish farming indices of respondents

\begin{tabular}{|c|c|c|c|}
\hline Farm operation indices & Category & Frequency & Percent respondent \\
\hline Water types used & Fresh water & 60 & 100.0 \\
\hline \multirow[t]{2}{*}{ Water sources } & $\begin{array}{l}\text { Rainwater only } \\
\text { Rain and groundwater }\end{array}$ & 23 & 38.3 \\
\hline & & 37 & 61.7 \\
\hline \multirow[t]{2}{*}{ Type of farming system } & Extensive & 10 & 16.7 \\
\hline & Semi-intensive & 50 & 83.3 \\
\hline \multirow[t]{2}{*}{ Total pond area } & $<0.5$ ha & 34 & 56.7 \\
\hline & $>0.5-1.0 \mathrm{ha}$ & 26 & 43.3 \\
\hline All ponds seasonal & Yes & 60 & 100.0 \\
\hline \multirow{3}{*}{$\begin{array}{l}\text { Presence of inlet } \\
\text { and outlets in ponds }\end{array}$} & Inlet and outlets in all ponds & 37 & 61.7 \\
\hline & $\begin{array}{l}\text { Inlet and outlets absent in } \\
\text { all ponds }\end{array}$ & 10 & 16.7 \\
\hline & $\begin{array}{l}\text { Inlet and outlets present in } \\
\text { some ponds }\end{array}$ & 13 & 21.6 \\
\hline \multirow[t]{3}{*}{ Types of culture systems } & Monoculture of African catfish & 35 & 58.3 \\
\hline & Monoculture of Nile tilapia & 2 & 3.3 \\
\hline & Polyculture of both & 23 & 38.4 \\
\hline \multirow[t]{3}{*}{ Preferred culture species } & Mixed/integrated aquaculture & 60 & 100.0 \\
\hline & Nile tilapia & 2 & 3.3 \\
\hline & African catfish & 58 & 96.7 \\
\hline Value addition to fish & Smoking & 9 & 15.0 \\
\hline
\end{tabular}

and floods (16.7\%) in Table 4. According to Table 5, 65.0\% of the respondents observed an increased number of years with drought over time, $65.0 \%$ observed a decreased number of flooding, while $16.7 \%$ were undecided. 
Table 3 Awareness on manifestations of climate change impacts among respondents

\begin{tabular}{lcc}
\hline Parameter & Frequency & $\begin{array}{c}\text { Percent } \\
\text { respond- } \\
\text { ent }\end{array}$ \\
& & 83.3 \\
Changes in climate condition & 50 & 100.0 \\
Presence of dry and wet seasons in a year & 60 & 80.0 \\
Rises in temperature and hotter dry seasons & 48 & 60.0 \\
Irregularities in seasons & 36 & 60.0 \\
Shortening of wet season & 36 & 60.0 \\
Drought & 36 & 60.0 \\
Decrease in river water volume in relation to rain & 36 & 45.0 \\
Erratic rainfall pattern & 27 & 45.0 \\
Floods & 27 & 83.3 \\
Low rainfall & 50 & 80.0 \\
Late onset of rainfall & 48 & 18.3 \\
Heavy rainfall in onset & 11 & 41.7 \\
Late offset of rainy season & 25 & 8.3 \\
Early offset of rainy season & 5 & 71.7 \\
Shortening of rainy season & 43 & 71.7 \\
Heavy land erosion & 43 & 18.3 \\
Increased frequency of violent storms & 11 & 18.3 \\
\hline
\end{tabular}

Table 4 Respondents' declared climate-induced extreme events that mostly negatively impacted fish farming

Table 5 Respondents experiences on extreme climateinduced events in fish farming over the years

\begin{tabular}{lll}
\hline Extreme climate events & Frequency & $\begin{array}{l}\text { Percent } \\
\text { respond- } \\
\text { ent }\end{array}$ \\
\hline Prolonged drought & 50 & 83.3 \\
Floods & 10 & 16.7 \\
\hline
\end{tabular}

\begin{tabular}{|c|c|c|c|}
\hline Trend of event & Perception & Frequency & $\begin{array}{l}\text { Percent } \\
\text { respond- } \\
\text { ent }\end{array}$ \\
\hline \multirow{3}{*}{$\begin{array}{l}\text { Has the number of } \\
\text { years with drought } \\
\text { increased or } \\
\text { decreased? }\end{array}$} & Decreased & 11 & 18.3 \\
\hline & Increased & 39 & 65.0 \\
\hline & No response & 10 & 16.7 \\
\hline \multirow{4}{*}{$\begin{array}{l}\text { Has the number of years } \\
\text { with floods increased } \\
\text { or decreased? }\end{array}$} & Decreased & 39 & 65.0 \\
\hline & Increased & 0 & 00.0 \\
\hline & Don't know & 11 & 18.3 \\
\hline & No response & 10 & 16.7 \\
\hline
\end{tabular}


Table 6 Respondents' listed adaptation strategies and factors that could enhance adaptation

\begin{tabular}{llcc}
\hline Parameters & Response & Frequency & $\begin{array}{c}\text { Percent } \\
\text { respond- } \\
\text { ents }\end{array}$ \\
\hline Adaptive strategies & & & 100 \\
Diversification to either crops or livestock & Yes & 60 & 50.0 \\
Diversification to other business/trading & Yes & 30 & 63.3 \\
Changed time of first stocking/breeding & Yes & 38 & 00.0 \\
Changed duration/number of stocking/breeding/unit/yr & Yes & 0 & 63.3 \\
Factors that have enhanced adaptation & & & 20.0 \\
Use of communication technologies & Yes & 38 & 16.7 \\
Membership of social groups & Yes & 12 & 10 \\
No response & & & \\
\hline
\end{tabular}

Table 7 Respondents' listed factors that constrained adaptation to climate change impact

\begin{tabular}{lcc}
\hline Factor & Frequency & $\begin{array}{c}\text { Percent } \\
\text { respond- } \\
\text { ents }\end{array}$ \\
\hline Presence of constraints to adaptation & 60 & 100.0 \\
Limited credit & 17 & 28.3 \\
Inadequate awareness & 37 & 61.7 \\
Inadequate access to land & 13 & 21.7 \\
Inappropriate stocking period & 10 & 16.7 \\
Inadequate supply of improved fish for stocking & 20 & 33.3 \\
Inadequate supply of fish farming inputs & 5 & 8.3 \\
Lack of affordable farming equipments & 5 & 8.3 \\
Little food for fish (inadequate feeding) & 18 & 30.0 \\
\hline
\end{tabular}

\subsection{Adaptation strategies, constraints to adaptation, and required interventions}

Identified adaptive strategies to climate change include diversification to crops or livestock $(100.0 \%)$, business/trade $(50.0 \%)$, and changed the time of first stocking/breeding $(63.3 \%)$. None $(00.0 \%)$ identified changed duration/number of stocking/breeding/ unit/yr. (Table 6). Respondents observed that communications technology (63.3\%) and membership of social groups (20.0\%) enhances adaptation. As presented in Table 7, all $(100.0 \%)$ respondents agreed that there were constraints to climate change adaptation. This includes inadequate awareness (61.7\%), inadequate supply of fish for stocking $(33.3 \%)$, little food for fish/or inadequate feeding (30.0\%). limited credit facility $(28.3 \%)$, inadequate access to land $(21.7 \%)$, inappropriate stocking period (16.7), inadequate supply of fish farming inputs $(8.3 \%)$, and lack of affordable farming equipment $(8.3 \%)$. The required interventions for improved resilience (Table 8) were tree planting and irrigation (63.3\%) and digging of underground water channels around ponds $(20.0 \%)$. 
Table 8 Respondents' listed required interventions for improved resilience to climate change impacts

\begin{tabular}{lll}
\hline Required intervention & Frequency & $\begin{array}{l}\text { Percent } \\
\text { respond- } \\
\text { ent }\end{array}$ \\
\hline $\begin{array}{l}\text { Digging water channels around } \\
\text { ponds }\end{array}$ & 12 & 20.0 \\
$\begin{array}{l}\text { Tree planting } \\
\text { Irrigation }\end{array}$ & 38 & 63.3 \\
\hline
\end{tabular}

\subsection{Significant predictors of climate impact adaptability among the socioeconomics and the farming operation indices of the fish farmers}

Tables 9, 10, and 11 show the results on estimators for adaptability in the socioeconomic and farming operation indices of the studied flood-prone fish farmers. In Table 9,

Table 9 Estimators for adaptation to climate change impact among the socioeconomics and farming operation indices of flood-prone fish farmers in Uganda

\begin{tabular}{|c|c|c|c|c|c|}
\hline \multirow[t]{2}{*}{ Model } & \multicolumn{2}{|c|}{ Unstandardized coefficients } & \multicolumn{2}{|c|}{ Standardized coefficients } & \multirow[t]{2}{*}{ Sig } \\
\hline & B & Std. Error & Beta & $\mathrm{t}$ & \\
\hline (Constant) & 75.16 & 49.04 & & 1.53 & 0.13 \\
\hline Age & -5.09 & 4.30 & -0.22 & -1.18 & 0.24 \\
\hline Religion & -3.20 & 1.83 & -0.32 & -1.74 & 0.09 \\
\hline Education & 1.07 & 1.52 & 0.11 & 0.70 & 0.49 \\
\hline Gender & 16.88 & 6.54 & 0.55 & 2.58 & 0.02 \\
\hline Marital status & 11.12 & 7.15 & 0.30 & 1.55 & 0.13 \\
\hline Household status & 4.02 & 3.44 & 0.29 & 1.17 & 0.25 \\
\hline Membership in social group & -18.09 & 17.64 & -0.83 & -1.02 & 0.31 \\
\hline Membership to social groups (farmers association) & -12.94 & 11.78 & -0.64 & -1.09 & 0.28 \\
\hline Communication technologies (phone) & -4.74 & 5.89 & -0.12 & -0.80 & 0.42 \\
\hline Communication technologies (radio) & -20.13 & 11.03 & -0.92 & -1.82 & 0.08 \\
\hline Communication technologies (television) & 0.56 & 17.22 & 0.01 & 0.03 & 0.97 \\
\hline Average annual income & -1.66 & 1.28 & -0.29 & -1.29 & 0.20 \\
\hline Knowledge source (government training) & -103.15 & 35.62 & -3.95 & -2.89 & 0.01 \\
\hline Knowledge source (NGO training) & -8.36 & 11.46 & -0.33 & -0.72 & 0.47 \\
\hline Knowledge source (other farmers) & 6.36 & 3.68 & 0.35 & 1.72 & 0.09 \\
\hline Number of activities mentioned as income source & 4.91 & 4.44 & 0.36 & 1.10 & 0.28 \\
\hline Farm size & 34.48 & 14.52 & 1.79 & 2.37 & $\mathbf{0 . 0 3}$ \\
\hline Water sources & 12.83 & 6.10 & 1.82 & 2.10 & 0.04 \\
\hline Type of farming system practiced & 8.40 & 7.44 & 0.37 & 1.12 & 0.27 \\
\hline Type of cultivation practiced & -29.53 & 16.66 & -1.41 & -1.77 & 0.09 \\
\hline Presence of inlet and outlets in ponds of farmers & -28.69 & 11.95 & -1.72 & -2.40 & 0.02 \\
\hline
\end{tabular}

Dependent variable: adaptation strategy;

*Significant indices $(p<0.05)$ were in bold 
Table 10 Model summary for regression of climate impact adaptation, socioeconomics and farming operation indices of flood-prone fish farmers in Uganda

\begin{tabular}{lllll}
\hline Model & $R$ & $R$ square & Adjusted $R$ square & Std. Error of the estimate \\
\hline 1 & $0.802^{\mathrm{a}}$ & 0.643 & 0.330 & 8.56769 \\
\hline
\end{tabular}

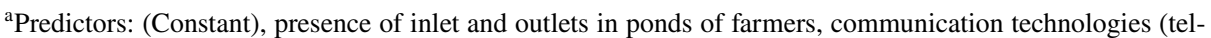
evision), marital status, type of farming system practiced, education, age, average annual income, religion, communication technologies (phone), knowledge source (other farmers), gender, number of activities mentioned as income source, communication technologies (radio), knowledge source (NGO training), household status, farm size, membership to social groups, water sources, type of cultivation practiced, membership in social group (farmers' association), knowledge source (government training)

Table 11 ANOVA for the regression of climate impact adaptation, socioeconomics and farming operation indices of flood-prone fish farmers in Uganda

\begin{tabular}{llllll}
\hline Model & Sum of squares & df & Mean square & F & Sig \\
\hline Regression & 3169.296 & 21 & 150.919 & 2.056 & $.045^{\mathrm{a}}$ \\
Residual & 1761.726 & 24 & 73.405 & & \\
Total & 4931.022 & 45 & & & \\
\hline
\end{tabular}

aPredictors: (Constant), presence of inlet and outlets in ponds of farmers, communication technologies (television), marital status, type of farming system practiced, education, age, average annual income, religion, communication technologies (phone), knowledge source (other farmers), gender, number of activities mentioned as income source, communication technologies (radio), knowledge source (NGO training), household status, farm size, membership to social groups, water sources, type of cultivation practiced, membership in social group (farmers association), knowledge source (government training)

gender (StdBeta $t=2.58$ ), government training (StdBeta $t=-2.89$ ), and farm size (StdBeta $t=2.37$ ) were the significant predictor among the SEI, while water sources (StdBeta $t=2.10$ ) and presence of inlet and outlets in ponds (StdBeta $t=-2.40$ ) were the significant predictors among the FOI at beta constant 75.16, $p<0.05$ (Table 9). The models' summary (Table 10) and ANOVA result (Table 11p) showed that the indices regressed at $R=0.802, R^{2}=0.64$, and $=0.045$.

\section{Discussion}

The assessed respondents were those who continued fish farming in the face of flood hazards in climate change impacted environment. This indicates that the respondents were vulnerable to climate-induced flooding but were adapting. It also follows that the respondents would likely be consistent in utilizing their current survival strategies to cope with future hazards. There is a need to discuss the results of the current survey highlighting the weaknesses and strengths in their adaptation potentials for improvement. This action would assist in projecting a framework for improved resilience which would be useful not only to the community but to communities in a similar scenario. 


\subsection{Socioeconomic profile of the fish farmers}

Climate adaptation strategies are risk management approaches. Understanding the socioeconomic situation is as important as knowledge of the likely future climate as vulnerable elements of society (Kerr and McLeod 2001). Society's capacity to adapt could be dependent on the prevailing socioeconomic situation through time. Discussions on the socioeconomic situation of the respondents and the needed inputs for adaptation framework are presented.

\subsubsection{Age, gender, education, and religion}

Gender influences the dynamics of climate impacts vulnerability (CARE Poverty, Environment and Climate Change Network, PECCN 2011). Each gender responds differently to climate risks, men having more adaptation opportunities than women (Takota et al. 2011). Since most of the $\mathrm{F}_{\mathrm{P}} \mathrm{FF}$ (83.3\%) were male (Sect. 3.1), it could be deduced that capacity building for enhanced efficient utilization of current male potential would assist adaptation. An effort aimed at increased exploration of the unique potentials of the female gender would also contribute to enhanced adaptability. Women play a significant role in processing, selling, and marketing (Gonzalez and Belemvire 2011). Females, especially women could engage in fish production; processing, value addition, and subsequent marketing of farmed fish in cases of premature fish harvest emanating from climate-mediated hazards, such as flood and drought. Women are innovative in the use of local knowledge in climate change adaptation (Abeka et al. 2012). Climate change and the associated flood/drought hazards impact the livelihood of affected fish farmers. The highlighted unique adaptive potentials of the female gender could be utilized for enhanced adaptation to this impact. Delivering information, resources, and technologies to women about appropriate practices on climate-smart strategy is important (FAO 2014). Framework involving disseminating climate-smart information, resources, and technologies to women, just as for men, in the vulnerable communities would be required in building their resilience through improved adaptation potentials. The majority of the vulnerable, but still farming respondents were adult, literate, and Christian. Ideally, maturity, knowledge, and faith could strengthen persistence in the face of hazards. This could indicate that age, education, and religion would have influenced response to hazards in the studied population. Support to encourage the farmers to continue farming to gain more experience in fish farming despite the confronting challenges would be helpful. Furthermore, the promotion of education and religious activities aimed at sharing knowledge on climate-smart techniques in flood-prone scenarios would likely be useful. This would assist in ensuring that vulnerable farmers continue farming despite the impacts of climate change and or flood hazards.

\subsubsection{Marital status, household size, income, and farm size}

Nearly all the respondents $(91.7 \%)$ were married. The mean family size was small $(2.02 \pm 0.73)$, but the majority $(48.3 \%)$ of the family were medium sized with 5-8 members. Being married and having a family size of 5-8 members may be beneficial in coping through collective effort to innovate for on-farm approaches in preventing flooding. It would also assist in providing support for the household head in the recovery of flooded fishes during the post-flood period. However, the dependence of a large number of people 
on the disaster/flood-prone farming activities would be injurious to socioeconomic capacity to adapt to hazards. More so, the majority of these respondents were relatively young in fish farming, had medium-size farms (0.5-1.0 ha), and were in low-income status (going by the standards of the World Bank Data Team 2018). Small ponds/farms are easier to manage; they are especially useful when there is a need to quickly circumvent climateinduced hazards such as flood, drought, and high pond water losses. However, maintenance of the 0.5 to 1.0 ha farm size alongside a family of 5-8 members would connote potential socioeconomic stressors in the low-income scenario. More so, these respondents are also vulnerable to flooding and its associated socioeconomic challenges. It could be deduced that the respondents' adaptive response to multiple hazards. Meanwhile, flooding would be low in this case. Such fish farmers would be easily destabilized in cases of climate-induced hazards. They could find it difficult to acquire adequate facilities to protect the whole 0.5-10 ha farm from flood while responding to other livelihood challenges. This scenario indicates potential stress on the socioeconomic condition of the low-income earner floodprone fish farmers.

The adaptation framework for this set of farmers should include strict adherence to small family size, other than medium or large-sized families. Diversification of the family members into other income sources that are not or less prone to flood and CCI could improve their adaptability. The fact that about half of the respondents were diversifying to other livelihood sources that are less prone to climate change and flooding (trading and public service) is positive in this direction. However, increase awareness creation on the adoption of this strategy should receive further boost among flood-prone fish farmers $\left(\mathrm{F}_{\mathrm{P}} \mathrm{FF}\right)$. Training and provisions on family planning strategies could assist to reduce family size. It would be necessary to educate the $\mathrm{F}_{\mathrm{P}} \mathrm{FF}$ on the need to reduce farm size in situations of low income to adequately cope with $\mathrm{CCI}$ and flood in the future. It has been clamored that developing countries must upgrade smallholder agriculture to achieve full potential by removing transactional barriers for enhanced productivity (IFAD 2012; Sjauw-Koen-Fa et al. 2016; London et al. 2010; Wiggins et al. 2010; Hazell et al. 2010). Improved adaptation potential would also include motivation for small-sized fish farm holding. There is also the need to facilitate policies liable to remove/reduce transactional barriers to encourage smallholders $\mathrm{F}_{\mathrm{P}} \mathrm{FF}$. Such action would contribute to increased CCI adaptive capacity and sustainable fish/food production.

\subsubsection{Association, communication, and training}

Most respondents were members of social groups, especially the fish farmers group, and they utilized communication technologies, especially mobile phones $(91.7 \%$ of respondents). This implies a strong potential for resistance, resilience, and response to hazards, indicative of adaptation. Membership of association facilitates collective effort toward adaptation. Information communication through mobile phones would facilitate support in case of emergency response to hazards. Both indicators would contribute to improved resilience. Membership of social groups and improved communication facilities are necessities as a component for an adaptive framework for climate risk-prone fish farmers and other communities in similar scenarios. It is important to note that some respondents reported the use of more than one communication facility. This is evident in the over one hundred percent total observed frequency of respondents in the communication facilities category in Table 1. The use of more than one communication channel indicates that respondents have 
alternatives and a certain degree of freedom to obtain and disseminate information. This implies adaptive tendencies for flexibility in communication channels by the respondents.

Knowledge is power. The majority of the $\mathrm{F}_{\mathrm{P}} \mathrm{FF}$ obtained knowledge of fish farming from government training (Sect. 3.1). Increased dependence on government training would likely enhance adaptability. However, this would have to be carefully done as a continuous dependence on government intervention for acquiring knowledge is not sustainable. In this regard, there is a need for caution, especially in low-income countries such as Uganda. The framework for adaptation should strengthen non-formal and non-governmental strategies alongside government intervention in imparting CCI adaptation and mitigation strategies. Indigenous knowledge and practices have helped local communities to adapt to climate change risks (MoSTE 2015). Hence, the exchange of local knowledge on climate impact adaptation among the $\mathrm{F}_{\mathrm{P}} \mathrm{FF}$ could be helpful. This would be the least-cost but sustainable knowledge sharing approach. In the meantime, membership of social and religious groups can be leveraged upon in the dissemination of knowledge on CCI adaptation of the fish farmers.

\subsection{Technical/farming operation profile of the fish farmers}

Technologies can be utilized to enable adaptation to CCI and increase resilience to climate stresses and shocks in communities. Technicalities involving the utilization of natural resources that communities already have in a more resilient and productive way could deepen adaptive tendency in fish farming. This is especially important in the face of natural disasters. Hard technologies have a critical role in helping societies reduce the risk from CCI, so are the soft technologies. The soft technologies include improved management practices, education, capacity building, governance, and cultural practices (ADB 2014). There is the general need to evolve accessible and affordable technologies for CCI adaptation at scales, especially among the small scale, poor, and risk-averse farming families in developing countries (Henderson 2018). In this regard, an array of hard technologies for fish farming in the face of climate-induced flooding have been presented (Oyebola et al. 2018), the socioeconomic adaptive tendencies of the flood-prone fish farmers in Uganda have been discussed in Sect. 4.1. Meanwhile, the adaptive tendencies in the fish farming management strategies of the $\mathrm{F}_{\mathrm{P}} \mathrm{FF}$ are discussed here. Interestingly, the farming profile of the respondent $\mathrm{F}_{\mathrm{P}} \mathrm{FF}$ revealed some potential adaptation tendencies but with some cautions. Water sources, farming systems, pond rearing facilities, culture systems, and value-addition strategies of the respondents are highlighted alongside suggestions for inclusion into the framework for improved adaptation to CCI and associated flooding hazards.

\subsubsection{Water sourcing for fish farming}

Climate influences the dynamics of the availability of natural water (Bates et al. 2008; Chalecki and Gleick 1999) and hydrological conditions (AIACC 2006). It also induces variability in the availability of natural water (Esqueda et al. 2011). All respondents utilized freshwater as expected in most landlocked communities. However, it is alarming that the respondents relied on natural water sources for fish farming. About $38.3 \%$ of respondents utilized rainwater only, while $61.7 \%$ combined rain with groundwater. High dependence on natural water sources would predispose any farming system to CCI. The water-use behavior of the respondents could emanate from the confidence that being flood prone is indicative of an abundance of natural water, whereas water regime in climate-prone communities 
would be vulnerable to fluctuations. This would negatively impact on sustainability and predictability of agricultural production. This water sourcing strategy indicates a potential weakness for CCI adaptation. Holistic adaptation framework for $\mathrm{F}_{\mathrm{P}} \mathrm{FF}$ would require education/training and awareness creation aimed at highlighting the risks of high dependence on natural water sources for fish farming in the face of exposure to flood and CCI. Interventions on trending climate-smart technologies for water management would be needed for improved CCI resilience of the respondents. Some of the existing soft and hard technologies for minimizing CCI adaptation highlighted by ADB (2014) could be useful in this regard.

\subsubsection{Farming systems and pond area}

Innovation in agriculture is an important response for effective and equitable adaptation and mitigation (Zilberman et al. 2018). Technology innovations are viable strategies for climate impact adaptation in agriculture (Asayehegn et al. 2017; Smithers and Blay-Palmer 2001). Meanwhile, farming techniques and farming facilities are important in this regard. All the respondents operate either extensive or semi-intensive fish farming systems, the majority $(83.3 \%)$ on semi-intensive. A majority had small-size pond areas $(<0.5 \mathrm{ha})$, a minority were medium-sized $(>0.5-1.0 \mathrm{ha})$, and the ponds were mainly seasonal. It is advantageous that the $\mathrm{F}_{\mathrm{P}} \mathrm{FF}$ had more small-sized total pond areas and were mainly operating a semi-extensive farming system. Conventionally, the semi-intensive fish farming system combines free range with little feed input supply. Conventional feed accounts for over 70 percent of production cost in fish farming; therefore, the practiced extensive and semiintensive farming system would be ideal for the poor hazard-prone farmers as production cost would be relatively small. Adoption of these low-cost fish farming techniques would reduce economic stress on the farmers. This alongside the use of small and medium-sized pond areas is potential adaptive strategies in managing low income in fish farming.

Advantages of the adopted farming system could be leveraged upon for adaptive framework for fish farming in flood and CCI-prone low-income communities. However, seasonality of the ponds could indicate the gross impact of respondents' dependence on natural water. This would have resulted in seasonal farming, and possibly a dwindling and season-based income from fish farming. This pattern of income would negatively impact their socioeconomic potential for adapting to CCI, as income would be skewed to the wet/rainy season. Meanwhile, the wet season is most prone to flooding. An appropriate framework would have to look into actions geared toward diversifying into income-generating activities that would not be season dependent.

\subsubsection{Presence of inlet and outlets in ponds}

Property owners and farmers in vulnerable regions will increasingly look at technologies that can help them adapt to potential floods. Adaptation technologies could involve crafting barriers around rivers, and using seeds and crops that are more resistant to floods (Talanoa 2010). Adaptation strategies in water resources and hydrology could include "hardware," use of ponds, wells, reservoirs, and rainwater harvesting; "software," increase water use efficiency and recycling; and "orgware," such as water user associations, and water pricing strategies (Markandya and Galarraga 2011).

The results showed that the respondents mostly utilized pond system for fish farming. This "hard" technology (ponds) is ancient to fish farming and has been the most used 
among fish farmers in low-income countries. This is probably due to its ease of construction, low cost of construction, and management. The use of pond systems by the respondents followed the usual trend in low-income countries, and it would be difficult to discourage its use. However, the technique is generally prone to flooding due to site selection issues (Oyebola et al. 2018). The need for continued use of the system despite its weakness has led to innovations on the installation of inlet and outlet pipes and the pipes' screening with netting materials. These features are especially important in the case of $\mathrm{F}_{\mathrm{P}} \mathrm{FF}$ to reduce the impact of flood hazards. Such action facilitates continued farming despite the threats from floods. Installation of inlet and outlets in the pond is a technical innovation for manipulation of water level, easy pond water inflow, and drainage. Ideally, all ponds should have inlet and outlet, as this technical approach assists in the fast management of waterrelated hazards. Screened inlet and outlets prevent pond invasion by aquatic pests in transit during the flood. Water can be easily drawn into the pond from other sources through inlets in times of drying pond water. Also, pond water could be removed through the outlet pipes in cases of flood-mobilized poor water quality, and changed water chemistry emanating from CCI. However, results in Sect. 3.2 indicated that only $61.7 \%$ of respondents had inlet and outlet present in all ponds.

The adaptive frame for these sets of farmers should emphasize enlightenment on the dangers of this technical flaw in the face of the impact of climate change and flooding. The farmers being 1-5 yrs old in fish farming would need technical assistance, educating them on standard pond features and other technical demands for fish farming. This action is critical especially in the face of climate-mediated hazards, such as flooding. The $\mathrm{F}_{\mathrm{P}} \mathrm{FF}$ will need more training on the highlighted. Knowledge of the manipulation of other "hard technologies" such as pond dykes and slopes, as specified by Christiansen et al. (2011) will also be required. Interestingly, some such adaptive hard technologies for fish farming in the flood-prone situation have been published (Oyebola et al. 2018). Increase awareness and training on these technologies would facilitate better water management, reduction in fish loss/escape, and pond invasion by alien plant and animal species during the flood.

\subsubsection{Culture systems and value addition}

Culture species and culture systems could indicate potential adaptive potential or vulnerability to hazards in fish farming. FAO/SPADA (2008) reported that most aquaculture in Africa has been practiced in small and hand-dug earthen farm ponds, typically stocked with tilapias and/or catfish. Mono, poly, and integrated culture of the catfish and tilapia species are popular among fish farmers in Africa. In agreement with this, 58.3\% of respondents practiced monoculture of African catfish (Clarias gariepinus), $3.3 \%$ monoculture of Nile tilapia (Oreochromis niloticus), 38.4\% practiced polyculture of African catfish and Nile tilapia in ponds. $100 \%$ practiced mixed/integrated aquaculture with either livestock or crop on farms; however, the respondents (96.7\%) preferred African catfish culture.

Catfish have been confirmed to be the most popular species for aquaculture in Uganda, contributing about 60 percent of aquaculture production (FAO 2019). The adoption of the species in case of flood and CCI-prone situation sound better when compared to tilapia. Compared to Tilapia, the species is highly versatile (De Moor and Bruton 1988), air breathing, and bottom dwelling. It would not be easily washed off by flood being bottom dwelling. In case of displacement from pond water during a flood, the most cultured Catfish, Clarias gariepinus could travel long distances on land using its pectoral spine and air-breathing facilities. These versatile and hardy natures could have mobilized its popularity in mono, poly, and integrated/ 
mixed farming culture systems. The species would be likable potential in adapting to flood and inclement CCI. Polyculture of the African catfish with tilapia in earthen pond increased yield and economic benefits (Limbu et al. 2017); the same trend was observed in its integrated aquaculture with agriculture (Jahan et al. 2013; Jah et al. 2018). It is laudable that the respondents were involved in the polyculture of these species, and all were practicing mixed/integrated fish and crop/livestock farming. These systems of stocking multiple fish and other agriculture species with probably differential resilience to CCI would be advantageous to product diversification. This would have a positive contribution to the adaptive potentials of the $F_{P} F F$. A sustainable framework for adaptive farming by $\mathrm{F}_{\mathrm{P}} \mathrm{FF}$ would need to strengthen the adoption of this system.

Value addition plays a vital role in improving economic returns in agriculture enterprises. It could be useful in adapting to flooding and other CCI. Small holder's value addition is a network of food-related businesses through which products move from production to consumption while gaining incremental value in the marketplace (Stevenson and Pirog 2013). Investments in value-adding supply chains could simultaneously provide opportunities, access to local markets, and advanced local economic growth (Kapstein et al. 2012). However, value addition is not popular among the respondents, as only $15.0 \%$ do fish smoking for value addition. It implies that most of the respondent fish farmers were not involved in any fish value addition; only a few farmers carry out fish smoking as value addition.

Apart from increasing the income of farmers, value addition such as fish smoking could serve as means of fish preservation from spoilage in cases of emergency fish harvest from hazards, when the market is not available. Smoking and any other value addition techniques would be an advantage for adapting in situations of occurrence of climate risks (drought and flood), which often force fish farmers to premature fish harvesting. Most of the time, premature fish stocks are small sized and may not be acceptable to some buyers of fresh fish. However, smoked or value-added small-sized fishes have diverse local utility for livelihood instead of being wasted. Canned small-sized fish can enjoy the international market. The low number of respondents practicing value addition indicates the need for inclusion of increased awareness on value addition or product diversification opportunities in catfish and tilapia farming in the management framework for the $\mathrm{F}_{\mathrm{P}} \mathrm{FF}$.

The structure of the farming operation of the $\mathrm{F}_{\mathrm{P}} \mathrm{FF}$ observed in the current study is similar to the general trend of a fish farming operation in Uganda, presented in the national aquaculture sector overview for Uganda (FAO 2019). The respondents may have been utilizing adaptive potentials of fish farming to cope with their situation; however, they would need to evolve unique strategies to increase adaptive tendencies for their peculiar situation. The earlier suggested instruments for inclusion in the framework for sustainable fish farming among the $\mathrm{F}_{\mathrm{P}} \mathrm{FF}$ would not only be useful for the focused respondents but probably for the entire fish farming communities in Uganda. The framework would need to highlight the need for sustainable actions geared toward the promotion of integration of economic activities and livelihood diversifications. Such actions would include value addition; human capacity building based on research-based community-relevant technologies, information sharing, and technology transfer. These would be instrumental in sustainable aquaculture development in the face of CCI and flooding in Uganda. 


\subsection{Awareness on climate change impacts, adaptation strategies, and required interventions}

\subsubsection{Awareness}

Awareness of CCI is imperative to achieve sustainability in developing countries (Shahid and Piracha 2016). Farmers must adapt farming practices to become more resilient to CCI (Fitzgerald 2016). It is desired that fish farmers are aware of diverse manifestations of CCI and that they would utilize relevant adaptive tools. Results in Sect. 3.3 indicated only 60.0 to 83.3 percent $\mathrm{F}_{\mathrm{P}} \mathrm{FF}$ were aware that $\mathrm{CCI}$ manifests in rises in temperature and hotter dry seasons, irregularities in seasons, shortening of the wet season, drought, decrease in river water volume concerning the rain, low rainfall, late onset of rainfall, shortening of rainy seasons and heavy land erosion. Meanwhile, 8.3 to 45.0 percent were aware of CCI indices such as erratic rainfall pattern, increased flood, the late offset of the rainy season, heavy rainfall at the onset of the season, early offset of the rainy season, and increased frequency of violent storms and increased frequency of heavy downpour of rain with storms.

A 60-80 percent of respondents' awareness on a CCI route could be considered popular, while awareness of $<50$ percent could be rated unpopular. In this regard, CCI manifestations relating to rainfall patterns and floods seem relatively unpopular among the $\mathrm{F}_{\mathrm{P}} \mathrm{FF}$. Ignorance would impair uptake of valuable climate mitigation/adaptation approaches (Shahid and Piracha 2016). The unpopular nature of flooding and fluctuating rainfall patterns is an important CCI vulnerability issue in this regard. The result implies that although some of the farmers were exposed, yet they could not link their experiences to CCI. Climate impact resilience planning should incorporate meaningful community engagement (The Council on Climate Preparedness and Resilience 2016). It would be beneficial to engage the $\mathrm{F}_{\mathrm{P}} \mathrm{FF}$ community for education on the various manifestations and adaptation strategies on CCI; especially concerning rainfall and flood. Such action would also enable enhanced uptake of technical innovations on fish farming in the face of CCI.

Warm temperatures can cause more evaporation of water, while changes in rainfall patterns can lead to more intense individual downpours, resulting in flood and drought (Trenberth 2011; Dai 2013). Floods and droughts are the main climatic extremes for proper management in Agriculture sectors (Watanabe et al 2018; OECD 2017). In agreement with this, the $\mathrm{F}_{\mathrm{P}} \mathrm{FF}$ identified flood and drought as the most challenging to them. Flood and drought impact on the economy of regions (Piratheeparajah and Rajendram 2014). They would reduce production and profitability, thus threatening the livelihood and food security of farmers. However, increased awareness on dimensions of these hazards, and strategies for adapting to the events is important in improving the respondents' adaptation potentials.

The majority (83.3\%) and minority (33.3\%) respondents, respectively, identified drought and flood as most impacting to fish farming. However, drought seems more popular than flood among the respondents. It is interesting that though the respondents were flood prone, drought seems to be more threatening to them than a flood. This indicates that the impact of the drought could have been more deeply felt compared to flood. The assessed $\mathrm{F}_{\mathrm{P}} \mathrm{FF}$ was not only prone to flood; they were also suffering from drought hazard at a higher intensity. The higher intensity of drought agrees with FAO (2016b, 2003) who observed that on a global scale, drought risks seem much greater than floods. However, each of the events would contribute quota impact on respondents with an effect on productivity; livelihood, and food security. Relative intervention on drought would need higher priority but, strategizing to adapt to both events would be necessary. Prioritizing drought management is 
further supported by the relatively higher proportion of respondents who observed increasing drought events compared to flood.

Respondents linked the climate hazards to experiences of low water levels in ponds and harvesting of premature fish. Experiencing these manifestations confirms that the respondents were exposed and vulnerable. Awareness of approaches aimed at circumventing limited water supply would have to be created for their improved adaptation. Innovations capable of utilizing the prematurely harvested fish resulting from drought, and flooding, in cases when the displaced fish are finally harvested/captured in a weak form, would be necessary. These farmers will need training on value addition options liable for utilization of the displaced and prematurely harvested fish, to reduce economic losses from the hazards. This would reduce the impact of the hazards on the livelihood of the farmers. The need for this has been discussed in the earlier section. There is the need to investigate and educate farmers on adaptable fish value addition options in climate-induced fish farm hazard scenarios.

\subsubsection{Adaptation strategies}

Communities exposed to hazards would normally adapt to survive. Meanwhile, adaptation could involve anticipating adverse effects, taking relevant actions to prevent and reduce potential damage, and exploring opportunities that may arise. Adaptation strategies could include processes by which strategies to moderate, cope with, and take advantage of the consequences of events are enhanced, developed, and implemented (UNDP 2005). In the meantime, adaptation strategy may vary across populations of locations; and adaptation strategies could be anticipatory, reactive, private, public, autonomous, and planned (IPCC TAR 2001).

In the current study, more of the respondents were adapting to prevailing conditions through diversification to either crops or livestock, diversifying to other business/trade, and changed the time of first stocking/breeding rather than through changed duration/number of stocking/breeding/unit/yr. The listed adaptive strategies could be classified as reactive-taking place after the impacts were felt, private-being initiated and implemented by individuals or households in the actor's rational self-interest, and autonomous-being triggered by changes in the natural, market, or welfare systems of the respondents. However, the inability of the respondents to highlight anticipatory, public, and planned adaptive strategies indicates that the actions of the respondents could be seen as more self-motivated and unstructured, being non-institutionalized. The individualistic adaptation approach would contribute to a heterogeneous CCI response structure. Mobilization for proactive public adaptation strategies using policy and management tools, and promoting sustainable communal-based adaptation strategies would be necessary.

The majority of the respondents (63.3\%) were adapting by changing the time of first stocking/breeding rather than changing their number of stockings per year. This indicates that the respondents did not want to reduce production per year, as this would negatively impact on their annual income and livelihood. Diversification into other livelihood sources could be indicative of positive innovations toward CCI among fish farmers (Dubey et al. 2017). The livelihood diversification strategy of half of the respondents (50.0\%) in which they engage in other trade is commendable; implying positive innovativeness for survival. New (2016) reported that sectors in agriculture in Africa are highly vulnerable to climate vulnerability because of their dependence on natural water supply sources. Diversification to either crops or livestock by all the respondents (100.0\%) is not CCI adaptation friendly. 
This is presumed to be non-CCI adaptation friendly because all the means of diversification are within the agriculture subsectors-also known to be appreciably vulnerable to CCI. A climate-smart approach through livelihood diversification to less water-dependent activities by more respondents would have to be supported for improved CCI adaptation by the community.

The discussed adaptation issues would be useful for end users such as the fish farmer's communities, policymakers, developmental partners, and extension officers in policy and management strides for reducing vulnerability to CCI. The opportunity of the social group's membership and the use of communication strategy (mobile phone) by the majority of the respondents can be utilized for creating awareness. They can also be utilized in the dissemination of valuable information to the fish farmers in this regard. However, respondents' highlighted constraints to CCI adaptation to include; limited credit facility, inadequate awareness on CCI, inadequate access to land, inadequate supply of improved fish for stocking, inadequate supply of fish farming inputs, inappropriate stocking period, and inadequate fish feeding. Logically, the highlighted could impair adaptation. Therefore, efforts aimed at circumvention of these socioeconomic and technical bottlenecks would be needed for improved adaptation. Framework for adaptation should be attractive to developmental partners in assisting the farmers in overcoming these challenges.

\subsubsection{Required interventions}

The grass-root opinion on specific needs could be the key to the provision of relevant assistance. Excluding the very people that adaptation resources must benefit in management strategies is risky, if such action would be effective (Poverty, Environment and Climate Change Network, PECCN 2011). In the current study, few respondents requested intervention on digging underground water channels around ponds; the majority opined that tree planting and installation of irrigation facilities are required. These respondents-identified intervention needs are important, as they could indicate the felt needs of the respondents. However, it is interesting that few respondents required the more flood-related adaptive approach of digging an underground channel around ponds. Some of the respondents provided responses indicating the need for more than one intervention. This reflected in over 100 percent of total respondents' frequency in this result category in the result (Table 8). Highlight of multiple choices by the respondents implies that combinations of these interventions could also assist adaptation. The highlighted intervention needs could have emanated from the farmers' experiences and knowledge about CCI adaptation and fish farming. It is therefore important to take cognizance of these highlighted factors in planning for their CCI adaptation. Government and development partners would need to improve interest in planning for and provision of these public adaptive incentives for enhanced adaptation of the $\mathrm{F}_{\mathrm{P}} \mathrm{FF}$. More so, adaptation technologies are often less capital intensive, more likely to be suitable for small-scale interventions, but have to be well adapted to the local context (UNFCCC 2006).

\subsection{Significant predictors of climate impact adaptability among the socioeconomics and the farming operation indices of the fish farmers}

Knowledge of significant estimators of adaptability in the respondent's socioeconomics and farming operation indices would enhance precision in planning for future climate events for 
the fish farmers. In the current study, some socioeconomic and farming operation indices were identified as significant estimators of the adaptive tendencies of the respondents. The highlighted significant parameters would be the most sensitive areas for prioritizing actions for interventions. The prediction models' summary $\left(R=0.802, R^{2}=0.64\right.$ and $\left.p=0.045\right)$, indicate that the model is reliable at least above average. The significant parameters were extracted from both the socioeconomics and the farming operation indices of the fish farmers. This confirms the necessity of taking adequate cognizance of these two adaptation sources in climate impact management for flood-prone fish farmers.

Gender, farm size, and water sources regressed positively with adaptation, while government training and presence of inlet and outlets in ponds regressed negatively. The result implies that improvement in the current status of gender, farm size, and water sources will positively improve adaptation to climate change among the respondent fish farmers. However, the continued trend of the government training and presence of inlet and outlets in ponds will reduce the adaptation capacity of the farmers. Therefore, the trend of gender, training, and farm size could significantly facilitate better socioeconomic strength for adaptation among flood-prone fish farmers. The presence of inlet and outlets in ponds and water sources would enhance their technical strength.

\section{Recommendations on framework for improved adaptive capacity}

Development of products that provide necessary tools to assess opportunities for climate impact adaptation could be underpinned by overviewing and identifying responses to past events (McKenzie Hedger et al. 2000). The trend of results in the current study provides useful opportunities for understanding the respondents' current potentials for adaptation to hazards. It also provides a tracking facility for their future response to CCI and flood associated risks. It is recommended that climate risk management for the flood-prone fish farmers be integrated into the planning process for the aquaculture sector in Uganda. Climate risk management strategies must be integrated into farming, business planning, and investments in the flood-prone communities. Such a strategy would need to make room for enabling environment for management of climate risk alongside social-economic development. Efforts aimed at continual monitor and dissemination of climate adaptations information across fish farmers are necessary. There is a need to develop robust infrastructure for the weather forecast to prepare for extremes, especially in locations that are at risk of flooding. Mobilization for exploration of the research-based adaptive potential of each vulnerable community would also be relevant in this regard. The highlighted information will be useful for the development of management frameworks for the focal groups. Development of community-based stakeholder groups for strategic oversight would assist lobby for adaptation policies and decision making in specified vulnerable communities. However, such stakeholders would have to be subjected to periodic training, awareness creation, and information dissemination on trending adaptation strategies of use in peculiar situations.

\section{Conclusions}

The study highlighted that the flood-prone fish farmers in the studied locations of climate hotspot Uganda have muddled through the combined impacts of flood and other climate change-related hazards. There is a high tendency that the flood-prone fish farmers would 
face further uncertainties and unknowns concerning climate-induced flood in the future. In the meantime, they possessed some intrinsic adaptive socioeconomic and technical potential to cope with climate-induced hazards to some extent. However, future CCI adaptation/vulnerability of the fish farmers would be influenced by their disposition of gender, farm size, water sources, government training, and presence of inlet and outlets in ponds. Improved adaptation of the $\mathrm{F}_{\mathrm{P}} \mathrm{FF}$ would require actions aimed at improved recognition and inclusion of the highlighted statistically identified significant predictors of their adaptive capacity, the farmers' identified intervention needs, and the discussed recommendations on a framework for improved adaptive capacity into the local and national framework for CCI management. Such actions would be beneficial to sustainable fish production for food security in the face of climate change impact in the region.

\section{Limitations of the study}

There is inadequate information specifying Kibuku and Gulu on some of the subjects of the current study. The literature tends to concentrate most on the regions other than specific locations within the regions. Statistics on agriculture in the selected location did not specifically cover the number of fish farmers in the districts. Fish farmers and other livestock producers were referred to as livestock producers without separation to fish subsection. It was difficult getting the actual record of the flood as it affects fish farmers in the study area. Most literature on flood events did not capture fish farming in these locations. This study was restricted to utilize the extension agents in identifying the fish farmers from the record and to administer the questionnaire due to lumped up record of fish farmers association with other livestock farmers.

Acknowledgements This research has been funded by UK aid from the UK government; however, the views expressed do not necessarily reflect the UK government's official policies. The CIRCLE Programme of the African Academy of Science and the Association of Commonwealth Universities is appreciated for hosting the research. Assistance of Dr Yazidhi Bamutaze (Makerere University, Uganda), Dr Oyet, and $\mathrm{Mr}$ Joseph is well appreciated.

Open Access This article is licensed under a Creative Commons Attribution 4.0 International License, which permits use, sharing, adaptation, distribution and reproduction in any medium or format, as long as you give appropriate credit to the original author(s) and the source, provide a link to the Creative Commons licence, and indicate if changes were made. The images or other third party material in this article are included in the article's Creative Commons licence, unless indicated otherwise in a credit line to the material. If material is not included in the article's Creative Commons licence and your intended use is not permitted by statutory regulation or exceeds the permitted use, you will need to obtain permission directly from the copyright holder. To view a copy of this licence, visit http://creativecommons.org/licenses/by/4.0/.

\section{References}

Abeka, S., Anwer, S., Huamaní, R. B. et al. (2012). Women farmers adapting to climate change. Four examples from three continents of women's use of local knowledge in climate change adaptation. Women Farmers I Climate Change Dialogue 09. Published by: Diakonisches Werk der EKD e.V. for "Brot für die Welt" and Diakonie Katastrophenhilfe Stafflenbergstraße 76 D-70184 Stuttgart Germany. pp. 52. https://www.unscn.org/uploads/web/news/Women-farmers-adapting-to-Climate-Change.pdf. Accessed 28 January 2019. 
ADB, Asian Development Bank (2014). Technologies to support climate change adaptation in developing Asia, Publication of the ADB November 2014. https://www.adb.org/publications/technologies-suppo rt-climate-change-adaptation-developing-asia. Accessed on 28 Jan 2019.

Adebo, G. M., \& Ayelari, T. A. (2011). Climate change and vulnerability of fish farmers in South-Western Nigeria. African Journal of Agricultural Research, 6(18), 4230-4238.

Adeleke, M. L., \& Omoboyeje, V. O. (2016). Effects of climate change on aquaculture production and management in Akure Metropolis, Ondo State, Nigeria. Nigerian Journal of Fisheries and Aquaculture, $4(1), 50-58$.

Adelodun, O. B. (2015). Participation of youth in Aquaculture. Journal of Aquaculture Research and Development, 6, 386-401. https://doi.org/10.4172/2155-9546.1000386.

AIACC, Assessments of Impacts, and Adaptations to Climate Change (2006). Vulnerability to climate change related water resource changes and extreme hydrological events in Southeast Asia. A final report submitted to Assessments of Impacts and Adaptations to Climate Change (AIACC), Project No. AS 07. Southeast Asia START Regional Center (SEA START).

Alfieri, L., Feyen, L., \& Di-Baldassarre, G. (2016). Increasing flood risk under climate change: a pan-European assessment of the benefits of four adaptation strategies. Climatic Change. https://doi.org/10.1007/ s10584-016-1641-1.

Allison, E. H., Adger, W. N., Badjeck, M. C. et al. (2005). Effects of climate change on the sustainability of capture and enhancement fisheries important to the poor: analysis of the vulnerability and adaptability of fisherfolk living in poverty. Project No. R4778J. Final Technical Report, Fisheries Management Science Programme, MRAG/DFID, London; 164.

Asayehegn, K., Iglesias, A., Triomphe, B., et al. (2017). The role of systems of innovation in adapting to climate change: the case of the kenyan coffee and dairy sectors (1). Journal of Innovation Economics and Management, 3(24), 202-208.

AWDR, African Water Development Report (2006). Freshwater Resources in Africa: 380pp. http://www. uneca.org/awich/AWDR\%202006/Freshwater\% 20Resources\%20in\%20Africa.pdf (viewed 14 November 2009)

Bates, B. C., Kundzewicz, Z. W., Wu, S., et al. (2008). Climate change and water; Technical paper for intergovernmental panel on climate change: Geneva, Switzerland, 2008.

Boko, M., Niang, I., Nyong, A., et al. (2007). Africa Climate Change 2007: Impacts, Adaptation, and Vulnerability. In M. L. Parry, O. F. Canziani, J. P. Palutikof, P. J. van der Linden, \& C. E. Hanson (Eds.), Contribution of Working Group II to the fourth assessment report of the intergovernmental panel on climate change (pp. 433-467). Cambridge: Cambridge University Press.

Bordoloi, R., \& Muzaddadi, A. U. (2014). Indigenous technical knowledge associated with disaster management and fisheries-related activities in the highest flood-affected district (Dhemaji) of Assam India. Indian Journal of Traditional knowledge, 14(3), 407-415.

CARE Poverty, Environment, and Climate Change Network PECCN (2011). Understanding vulnerability to climate change: insights from the application of CARE's Climate Vulnerability and Capacity Analysis (CVCA) Methodology. CARE International Poverty, Environment, and Climate Change Network (PECCN), 2011.24PP. www.careclimatechange.org.

Chalecki, E. L., \& Gleick, P. H. (1999). A framework of ordered climate effects on water resources: a comprehensive bibliography. Journal of American Water Resources Association, 35, 1657-1665.

Christiansen, L., Olthoff, A., Trærup, S., (eds.), (2011) Technologies for adaptation: perspectives and practical experiences, UNEP Ris $\emptyset$ Centre, Roskilde, 2011. Available online at https://wedocs.unep.org/bitst ream/handle/20.500.11822/8040/-Technology\%20Transfer\%20Perspectives\%20Series_\%20Technolo gies $\% 20$ for $\% 20$ Adaptation $\% 20 \% 20 \% 20$ Perspectives $\% 20$ and $\% 20$ Practical\%20Experiences-20111073. pdf? sequence $=3 \&$ is Allowed=y. 28 January 2019.

Clements, R., Haggar, J., Quezada, A., Torres J. (2011). Technologies for climate change adaptation-agriculture sector. In X. Zhu (Ed.). Practical action Technology challenging poverty.GEF/UNEP TNA Guidebook Series UNEP Ris $\varnothing$ Centre on Energy, Climate and Sustainable Development Risø DTU National Laboratory for Sustainable Energy, Roskilde Denmark. http://tech-action.org/ Technologies for climate change adaptation-agriculture sector. Accessed 28 January 2019.

Coulibaly, A., Ouattara, A., Koné, T., et al. (2007). First results of floating cage culture of the African catfish Heterobranchus longifilis Valenciennes, 1840: Effect of stocking density on survival and growth rates. Aquaculture, 263, 61-67.

Dai, A. (2013). Increasing drought under global warming in observations and models. Nature Climate Change, 3, 52-58.

Davies, R. (2017). Uganda-2,000 Displaced by Floods in Northern Region, Deadly Landslide in Western Region. Floodlist, 25 August 2017. Retrieved from 29 Jan 2018 http://floodlist.com/africa/ugand a-floods-northern-region-august-2017. 
De Moor, I. J., \& Bruton, M. N. (1988). Atlas of alien and translocated indigenous aquatic animals in southern Africa. A report of the committee for nature conservation research national programme for ecosystem research. South African Scientific Programmes Report No. 144. 310 p. Port Elizabeth, South Africa.

Dubey, S. K., Trivedi, R. K., \& Chand, B. K. (2017). Farmers' perceptions of climate change, impacts on freshwater aquaculture, and adaptation strategies in climatic change hotspots: A case of the Indian Sundarban delta. Environmental Development, 21, 38-51.

Environmental Alert (2010). Climate Change in Uganda: Insights for Long-Term Adaptation and Building Community Resilience. An Issues Paper, July 2010. pp 36. http://envalert.org/wp-content/uploa ds/2016/06/Climate-Change-Issues-paper.pdf.

Esqueda, G. S., Ospina-Noreña, J. E., Gay-García, C., et al. (2011). Vulnerability of water resources to climate change scenarios. Impacts on the Irrigation Districts in the Guayalejo-Tamesi River Basin, Tamaulipas, México, Atmósfera, 24(1), 7p.

F.A.O. (2016). The State of world fisheries and aquaculture 2016 (p. 200). FAO, Rome: Contributing to food security and nutrition for all.

FAO (2016b). The impact of disasters on agriculture and food security, FAO, Food and Agriculture Organization of the United Nations, Rome. Retrieved from 4th August 2018 http://www.fao.org/3/a-i5128 e.pdf.

FAO (2003). Unlocking the Water Potential of Agriculture, FAO Food, and Agriculture Organization of the United Nation, Rome, 54pp. Retrieved from 4th August 2018 http://www.fao.org/docrep/006/y4525e/ y4525e00.htm\#Contents.

FAO (2010). World Aquaculture 2010, Aquaculture service of the fisheries and aquaculture resources use and conservation division. FAO fisheries and aquaculture technical paper 500/1. Rome.

FAO (2014). Transitioning towards climate-smart agriculture in Kenya; linking research, practice, and policy. http://www.fao.org/climatechange/42101-052030dc948c02b143ca95a7f96cdc7bb.pdf

FAO (2019). National aquaculture sector overview: Uganda, fisheries and aquaculture department, e-bulletin, Food, and agriculture organization of the United Nations, Rome. Retrieved from 31 January 2019 http://www.fao.org/fishery/countrysector/naso_uganda/en.

FAO/SPADA (2008) SPADA: Special Programme for Aquaculture Development in Africa, Aquaculture: an investment in the future FAO: Department of Fisheries and Aquaculture and the Regional Office for Africa. Retrieved from 31 January 2019. http://www.fao.org/uploads/tx_chcforum/SPADAv6.[jm]28Jul08[g].pdf.

Fitzgerald, A. G. (2016). Farmer Resiliency in a Changing Climate: A Comparative Study of Massachusetts and Vermont Farmers. UVM Honors College Senior Theses. Paper 103.

Freeman, O. E. (2017). Impact of climate change on aquaculture and fisheries in Nigeria; A review. International Journal of Multidisciplinary Research and Development, 4(1), 53-59.

Gabriel, U. U., Akinrotimi, O. A., Belibele, D. O., et al. (2007). locally produced fish food: Potentials for aquaculture development in Sub-Saharan Africa. African Journal of Agricultural Research, 2(7), 287-295.

Gemeda, D. O., \& Sima, A. D. (2015). Review: The impacts of climate change on the African continent and the way forward. Journal of Ecology and the Natural Environment, 7(10), 256-262. https://doi. org/10.5897/JENE2015.0533.

Glantz, M. H. (ed.). (1988). Societal responses to regional Climatic Change: Forecasting by Analogy. Boulder, CO: Westview Press. Boulder, Colo., USA.

Glantz, M. H., Kelman, I. (2013). Thoughts on Dealing with Climate Change As if the Future Matters. International Journal of Disaster Risk Science, 4(1), 1-8. https://doi.org/10.1007/s13753-013-0002-1.

González, A. R., \& Belemvire, A. (2011). Climate Change and Women Farmers in Burkina Faso. Oxfam Research Report, July 2011. pp. 56.

Hazell, P., Steve, W., \& Andrew, D. (2010). The future of small farms. World Development, 38(10), 1349-1361.

Henderson, C. (2018). 'Technology' enabling adaptation to climate change. practical action, June 11th, 2018. Retrieved from 28 January 2019 https://practicalaction.org/blog/programmes/climate_change/ technology-enabling-adaptation-to-climate-change/.

Hepworth, N. D. (2010). Climate change vulnerability and adaptation preparedness in Uganda. Nairobi, Kenya: Heinrich Böll Foundation.

Hepworth, N., \& Goulden, M. (2008). Climate Change in Uganda: Understanding the implications and appraising the response, LTS International, Edinburgh. http://abovewhispers.com/2017/04/19/ugand a-one-killed-floods-cut-off-mbale-tirinyi-highway/ 
IFAD, International Fund for Agricultural Development (2012). Sustainable smallholder agriculture: Feeding the world, protecting the planet. IFAD, Rome. Thirty-fifth Session of IFAD's Governing Council, February. http://www.ifad.org/events/gc/35/doc/proceeding.pdf

IFRC (2007). Floods continue to ravage Uganda Thousands risk lives as they Cross cut off flooded areas 2007 0:00 CET https://www.ifrc.org/ar/news-and-media/news-stories/afric a/uganda/floods-continue-to-ravage-uganda/

IPCC TAR (2001). Climate Change 2001: Risk management in agriculture water use IN FAO 2003. Unlocking the water potential of agriculture. FAO food and agriculture organization of the United Nation, Rome, 54pp. Retrieved from 4 August 2018 http://www.fao.org/docrep/006/y4525e/y4525 e00.htm\#Contents

IPCC. Intergovernmental Panel on Climate Change (2012). In Field C. B., Barros V., Stocker T. F. et al. (eds.) Managing the risks of extreme events and disasters to advance climate change adaptation. A special report of working groups I and II of the Intergovernmental Panel on Climate Change (IPCC). Cambridge University Press: Cambridge, UK/New York, p 582.

Ipinjolu, J. K., Magawata, I., \& Shinkafi, B. A. (2014). Potential impact of climate change on fisheries and aquaculture in Nigeria. Journal of Fisheries and Aquatic Science, 9, 338-344.

Jahan, K. M., Crissman, C., \& Antle, J. (2013) Economic and Social Impacts of Integrated AquacultureAgriculture Technologies in Bangladesh. CGIAR Research Program on Aquatic Agricultural Systems. Penang, Malaysia. Working Paper: AAS-2013-02

Kahare, P. (2014) Climate Change and Africa: new report outlines continent's hotspots. African Arguments, June 3, 2014. Retrieved from August 2018 http://africanarguments.org/2014/06/03/climatechange-and-africa-new-report-outlines-continents-hotspots-by-peter-kahare.

Kapstein, E. B., Kim, R., Eggeling, H. (2012). Socio-Economic Impact of IFC Financing in Ghana-An Assessment of Employment and Value-added -IFC Final Report, November 2012.

Kerr, A., \& McLeod, A. (2001). Potential Adaptation Strategies For Climate Change In Scotland. University of Edinburgh, Scottish Executive Central Research Unit, Saughton House, Broomhouse Drive, Edinburgh EH11 3XA. https://www.ukcip.org.uk/wp-content/PDFs/Potential_Adaptation _Scotland_tech.pdf

Kolyangha M., (2017). Uganda: One Killed As Floods Cut Off Mbale-Tirinyi Highway This Day in History

Limbu, S. M., Shoko, A. P., Lamtane, H. A., et al. (2017). The fish polyculture system integrated with vegetable farming improves the yield and economic benefits of small-scale farmers. Aquaculture Research, 48(7), 3631-4364.

London, T., Ravi, A., \& Sateen, S. (2010). Creating mutual value: Lessons learned from ventures serving the base of the pyramid producers. Journal of Business Research, 63, 582-594.

Markandya, A., \& Galarraga, I. (2011). Technologies for adaptation: an economic perspective. In: Christiansen, L. et al. (ed.) Technologies for adaptation: perspectives and practical experiences. UNEP Ris $\emptyset$ Centre. Roskilde, Denmark.

McKenzie-Hedger, M., Gawith, M., Brown, M, (2000) Climate Change: Assessing the impacts-identifying responses (Report of the UK Climate Impacts Programme) July 2000.

Mer (2015). Climate Change Profile UGANDA. Netherland commission for environmental assessment. Dutch sustainability unit.9 July 2015. HTTP; climatehelpdesk@ minbuza.nl

MoSTE (2015). Indigenous and Local Knowledge and Practices for Climate Resilience in Nepal, Mainstreaming Climate Change Risk Management in Development, Ministry of Science, Technology, and Environment (MoSTE), Kathmandu, Nepal.

Muwaga, B. K., Macha, E., Michael, M. et al. (2007) Report on the rapid nutrition assessment in the flood-affected districts of Lango, Teso, and Elgon sub-regions of Uganda. November 2007. Wfp. http://www.unicef.org > Uganda_Fa_Floods_2007_2

Mwongera, C. K. M., Shikuku, J., Twyman, L., et al. (2014). Rapid Rural Appraisal Report of Northern Uganda; Semantic Scholar February-March 2014. pp 82 https://www.semanticscholar.org/paper/ Rapid-Rural-Appraisal-Report-of-Northern-Uganda-Mwongera-Shikuku/c7051424433a0d9aa741 0fb432c5a2245425251c

Nandi, J. A., Gunn, P., \& Adegboye, G. A. (2014). Assessment of Fish Farmers'Livelihood and Poverty Status in Delta State, Nigeria. Agriculture, Forestry, and Fisheries, 3(5), 427-433. https://doi. org/10.11648/j.aff.20140305.26.

Nelly, A., Isyagi, K., Veverica, L. et al. (2009). Manual for the Commercial Pond Production of the African Catfish in Uganda. USAID and Fisheries investment for sustainable harvest. Cooperative Agreement: 617-A-00-05-00003-00. pp. 222.

New, M. (2016) Understanding, Reducing and Managing African Climate Risk; www.axa.com 
OECD. (2017). Mitigating droughts and floods in agriculture. Agriculture Policy Note 2017. Retrieved from 4 August 2018 https://www.oecd.org/tad/policynotes/Mitigating\%20droughts\%20and\%20floods\%20 in\%20agriculture.pdf.

Olaifa, F. E (2015) Food security: The perspective of aquaculture and fisheries; 2014/2015 Faculty lecture, Faculty of Agriculture \& Forestry, University of Ibadan, delivered on 20 May 2015. Ibadan University Press. pp. 58.

Oratungye, K. J., Oludhe, C., Manene, M. M., et al. (2016). A multivariate analysis approach in determining potential hotspots of seasonal rainfall change over Uganda. International Journal of Statistics and Applied Mathematics, 2(1), 31-41.

Oyebola, O. O., Efitre, J., Falaye, A. E., et al. (2018). Agriculture in the Face of Climate-Mediated Flooding in Tropical Africa: Technical Innovations of Fish Farmers in Southwestern Nigeria. In: Leal Filho W. (eds) Handbook of Climate Change Resilience. pp 1-19 Springer, Cham. Online ISBN 978-3-31971025-9. https://doi.org/https://doi.org/10.1007/978-3-319-71025-9_163-1

Parry, M. L. (2000). Assessment of potential effects and adaptations for climate change in europe: The europe ACACIA project. Norwich, UK: Jackson Environment Institute, University of East Anglia.

Piratheeparajah, N., \& Rajendram, K. (2014). Impacts of flood and drought hazards on the economy of the Northern Region of Sri Lanka. Journal of Economics and Sustainable Development, 5(13), 31-44.

Rhodes, E., Axsen, J., \& Jaccard, M. (2014). Does effective climate policy require well-informed citizen support? Global Environmental Change, 29, 92-104.

Sarker, A. K., Datta, G. C., Razzak, M. A., et al (2011). Training Manual on Improved Tilapia Culture and Dyke Cropping in Pond/Gher: A Course Manual for Tilapia Farmers. Cereal Systems Initiative for South Asia in Bangladesh (CSISA-BD) Project WorldFish Center, Banani, Dhaka-1213.

Serdeczny, O., Adams, S., \& Baarsch, F. (2016). Climate change impacts in Sub-Saharan Africa from physical changes to their social repercussions. Regional Environmental Change. https://doi.org/10.1007/ s10113-015-0910-2.

Shahid, Z., \& Piracha, A. (2016). Awareness of Climate Change Impacts and Adaptation at Local Level in Punjab, Pakistan. In B. Maheshwari, V. Singh, \& B. Thoradeniya (Eds.), Balanced Urban Development: Options and Strategies for Liveable Cities (p. 76). Cham, RC, Bangkok, Thailand: Water Science and Technology Library, Springe.

Sjauw-Koen-Fa, A., Blok, V., \& Omtac, S. W. F. (2016). Critical success factors for smallholder inclusion in high value-adding supply chains by food and agribusiness multinational enterprises. International Food and Agribusiness Management Review, 19(1), 84-112.

Smithers, J., \& Blay-Palmer, A. (2001). Technology innovation as a strategy for climate adaptation in agriculture. Applied Geography., 21(2), 175-197. https://doi.org/10.1016/S0143-6228(01)00004-2.

Stevenson, G. W., \& Pirog, R. (2013). Values-based food supply chains: Strategies for agrifood enterprises-of-the-middle. http://www.cias.wisc.edu/wp-content/uploads/2013/04/ valuechainstrategiesfinal072513.pdf

Takota, T., Nyariki, D., \& Mkwambisi, D. (2011). Gender vulnerability to climate variability and household food insecurity. Climate and Development, 3(4), 298-330.

Talanoa, S. (2010). 10adaptation technologies, Climate Action, 22 December 2010. Retrieved from 28 January 2019 http://www.climateaction.org/news/10_adaptation_technologies.

The Council on Climate Preparedness and Resilience (2016). Opportunities to Enhance the Nation's Resilience to Climate Change. The White House Washington. Retrieved from 4 August 2018 https://toolk it.climate.gov/sites/default/files/finalresilienceopportunitiesreport,pdf.

The State Of Uganda Population Report (2009) Addressing the Effects of Climate Change on Migration Patterns and Women, by UNFPA Uganda. http://library.health.go.ug/download/file/fid/2064. Accessed 28 January 2019

The Teso Bukedea District Hazard, Risk, and Vulnerability Profile (2014). https://www.undp.org

Trenberth, K. E. (2011). Changes in precipitation with climate change. Climate Research, 47, 123-138.

Uganda Bureau of Statistics. (2017). The National Population and Housing Census 2014-Area Specific Profile Series. Uganda: Kampala.

Uganda climate change vulnerability assessment report. (2013). USAID African and Latin American Resilience to Climate Change (ARCC) August 2013. https://www.climatelinks.org/sites/default/files/asset/ document/ARCC-Uganda\%2520VA-Report.pdf.

Uganda flood map (2020). Licensed under CC BY-SA. (C) 2020 FloodMap.net, Developed by Sameer Burle https://www.floodmap.net/?1l=1.083462,33.803558\&z=10\&e=1102) Accessed 14 march 2020

Uganda Humanitarian Profile (2012). The Directorate of Disaster Preparedness and Management of OPM. http://opm.go.ug/manage/pdfs/DISASTER\%20POLICY.pdf

Uganda IPC. (2017). Report of the integrated food security phase classification analysis for Uganda, IPC integrated food security phase classification, evidence, and standard for better food security decisions, 
Uganda IPCC technical working group January 2017 http://www.ipcinfo.org/fileadmin/user_upload/ ipcinfo/docs/1_IPC_Uganda_AcuteFI_Report_Jan-March2017.pdf). Accessed 14 march 2020.

UNDP, United Nations Developmental Programme (2005). OECD 2006 Adaptation to Climate Change: Key Terms. Retrieved from on 4 August 2018 COM/ENV/EPOC/IEA/SLT(2006)1.http://www.oecd. org/environment/cc/36736773.pdf.

UNFCCC, United Nations Framework Convention on Climate Change (2007). Climate change: impacts, vulnerabilities, and adaptation in developing countries. Retrieved from 4 August $2018 \mathrm{https} / /$ unfcc c.int/resource/docs/publications/impacts.pdf.

UNFCCC, United Nations Framework Convention on Climate Change. (2006). Technology for adaptation to climate change. Bonn, Germany: UNFCCC.

UNWFP/UNICEF/MOH (2007). Reports on the rapid nutrition assessment in the flood-affected districts of Lango, Teso, and Elgon Subregions of Uganda. WFP and UNICEF.

Watanabe, T., Cullmann, J., Pathak, C.S. et al, (2018). Management of climatic extremes with focus on floods and droughts in agriculture. Irrigation and Drainage Volume 67, Issue1 Special Issue: Selected Papers of the 2nd World Irrigation Forum February 2018; pp. 29-42.

Wiggins, W., Johann, K., \& Llambí, L. (2010). The future of small farms. World Development, 38(10), $1341-1348$.

World Bank. (2008). The world development report 2008: Agriculture for development. Washington, DC: Word Bank.

World Bank Data Team (2018). New Country Classifications by Income Level: 2018-2019. The world bank IBRD-IDA. https://blogs.worldbank.org/opendata/new-country-classifications-income-level $-2018-2019$

Zilberman, D., Lipper, L., McCarthy, N., et al. (2018). Innovations in Response to Climate Change. In L. Lipper, N. McCarthy, D. Zilberman, S. Asfaw, \& G. Branca (Eds.), Climate-Smart Agriculture Natural Resource Management and Policy 52, Springer. Switzerland: Cham.

Publisher's Note Springer Nature remains neutral with regard to jurisdictional claims in published maps and institutional affiliations. 